\title{
Letramentos acadêmicos: epistemologias, práticas de escrita e experiências pedagógicas em interface no ensino superior
}

\begin{abstract}
Cynthia Agra de Brito Neves ${ }^{1}$
Programa de Pós-Graduação em Linguística Aplicada, Universidade Estadual de Campinas - UNICAMP, Campinas, SP, Brasil

Fernanda Correa Silveira Galli ${ }^{2}$

Departamento de Letras, Universidade Federal de Pernambuco - UFPE, Recife, PE, Brasil

Guillaume Nassau ${ }^{3}$

Departamento de Letras e Ciências Humanas, Université de Lorraine - UL, Nancy, França
\end{abstract}

\section{Apresentação}

A perspectiva de estudos dos letramentos acadêmicos, nos últimos anos, tem proporcionado discussões muito férteis, em especial no âmbito da Linguística Aplicada, haja vista o número de pesquisas teórico-práticas desenvolvidas sobre o tema no Brasil, as quais possibilitam discussões e reflexões críticas sobre práticas de ensino e aprendizagem de leitura e escrita, tanto em língua materna quanto em língua estrangeira. Ainda que o conceito de letramentos acadêmicos tenha sido cunhado no âmbito dos estudos de letramentos em contexto universitário, ele pode ser também abordado em outros contextos de ensino, na medida em que considera a leitura e a escrita como práticas sociais (BARTON, 1994; GEE, 1996; STREET, 1984, 1995) que se diferenciam de acordo com o contexto, a cultura e o gênero.

Este dossiê temático - intitulado: Letramentos acadêmicos: epistemologias, práticas de escrita e experiências pedagógicas em interface no ensino superior -, portanto, tem como proposta, por um lado, apresentar reflexões de caráter epistemológico em torno da escrita no ensino superior e ampliar as possibilidades de recortes e articulações teórico-metodológicos no estudo dos letramentos acadêmicos e seus desdobramentos; de outro, fortalecer perspectivas de estudo que visam a trazer resultados sobre dispositivos didáticos e práticas

\footnotetext{
${ }^{1}$ Doutora em Linguística Aplicada (Universidade Estadual de Campinas - UNICAMP), Docente do Departamento de Linguística Aplicada (DLA), do Instituto de Estudos da Linguagem (IEL), na Universidade Estadual de Campinas (UNICAMP). Orcid: https://orcid.org/0000-0002-5592-4409

E-mail: cynneves@unicamp.br ou cynthiaagrabneves@gmail.com

${ }^{2}$ Doutora em Linguística Aplicada (Universidade Estadual de Campinas - UNICAMP), Docente do Departamento de Letras, do Centro de Comunicação e Artes (CAC), na Universidade Federal de Pernambuco (UFPE). Orcid: https://orcid.org/0000-0002-4499-2908

E-mail: fernanda.galli@ufpe.br ou fcsgalli@hotmail.com

${ }^{3}$ Maître de conférence (Université de Lorraine), Nancy.

E-mail:nassau5@univ-lorraine.fr ou guillaume.nassau@univ-lorraine.fr
} 
pedagógicas adotados na formação superior.

O presente dossiê é também um desdobramento das atividades desenvolvidas em uma esfera mais ampla do Projeto Capes/Cofecub 834/15 (2015-2018), nomeado Discurso acadêmico na pesquisa e no ensino: questões em torno da apropriação da palavra de outrem [Le discours universitaire dans la recherche et l'enseignement: questions autour de l'appropriation de la parole d'autrui], uma parceria entre universidades brasileiras (PUC-Minas, UNESP-SJRP, UNICAMP e USP) e francesas (Université de Lorraine, Université Charles-deGaulle - Lille 3 e Université Grenoble Alpes). O Projeto, com duração de quatro anos consecutivos, teve a coordenação da Profa. Dra. Juliana Alves Assis (no Brasil) e da Profa. Dra. Sophie Bailly (Université de Lorraine).

A proposta de publicação do dossiê foi concebida no encerramento dessas atividades, ${ }^{4}$ como forma de divulgar as pesquisas realizadas pelos integrantes do Projeto, assim como acolher outros trabalhos sobre o tema dos letramentos acadêmicos. Integram, por conseguinte, este volume, artigos que têm como objeto de reflexão as práticas de escrita no ensino superior e versam em torno de cinco eixos temáticos, a saber: 1) autoria, 2) a relação com a palavra de outrem, 3) dispositivos e recursos didáticos, 4) sistemas de métrica de citações e 5) gêneros do discurso.

O primeiro eixo é composto por um artigo, intitulado Autoria e internacionalização na escrita acadêmica: análise da principal organização profissional das engenharias elétrica e eletrônica, no qual Larissa Giacometti Paris e Rómina de Mello Laranjeira buscam identificar e analisar, sob uma perspectiva de pesquisa qualitativo-interpretativa, as concepções de escrita acadêmica do Instituto de Engenheiros Eletricistas e Eletrônicos (IEEE). As autoras analisam, em documentos institucionais, os artigos científicos publicados pelo IEEE, com foco em duas concepções que envolvem as produções científicas: autoria e internacionalização. Como resultado, evidenciam as relações de poder institucional implícitas na definição de autoria e o predomínio de habilidades técnicas nos artigos científicos escritos em inglês, o que beneficia apenas os nativos da língua e coloca em xeque o projeto de internacionalização da ciência.

O segundo eixo reúne três textos que tematizam a relação com a palavra de outrem. Em A dimensão interdiscursiva do dizer na escrita científica: o diálogo com a palavra de outrem em artigos científicos de jovens pesquisadores, José Cezinaldo Rocha Bessa examina as maneiras sutis e complexas com que dez estudantes de mestrado elaboram seus textos acadêmico-científicos com base nas palavras dos outros. Apoiado na abordagem dialógica da linguagem sustentada pelos teóricos do Círculo de Bakhtin, Bessa conclui que o jovem pesquisador, ao apropriar-se da escrita científica e dialogar interdiscursivamente com as palavras de outrem, revela-se marcado por práticas citacionais, tanto no plano da forma quanto do conteúdo, que não são consideradas aceitáveis pelas convenções acadêmicocientíficas.

\footnotetext{
${ }^{4}$ No Seminário sobre letramentos acadêmicos: epistemologias e práticas em interface, realizado na PUC-Minas, nos dias 12 e 13 de março de 2018, sob coordenação da Profa. Dra. Juliana Alves Assis.
} 
A constatação de Bessa pode ser recuperada na provocação levantada por Sibely Oliveira Silva e Françoise Boch: "Como construir o estatuto de autor quando se é estudante?", em Dialogar com o discurso de outrem na escrita acadêmica ou como construir uma posição de autor. Nesse artigo, as autoras analisam textos acadêmicos produzidos por estudantes do curso de Letras a fim de identificar os diferentes procedimentos linguístico-textuais, discursivos e enunciativos utilizados por eles quando dialogam com o discurso de outrem na escrita acadêmica. Elas discutem os efeitos dessas escolhas - cujas normas são por vezes bastante representadas nos discursos que circulam na universidade, mas pouco abordadas nos manuais de redação para os estudantes - na construção autoral de seus textos.

Juliana Alves Assis, em Discursos de orientadores brasileiros e franceses no e sobre o feedback aos textos de seus mestrandos e doutorandos: um olhar sobre critérios e expedientes em torno da apropriação da palavra de outrem na escrita acadêmica, aborda a utilização do discurso de outrem em textos produzidos por pós-graduandos de universidades brasileiras e francesas. Ancorada na perspectiva bakhtiniana, Assis reflete sobre a função do feedback escrito pelo professor orientador com relação aos textos de seus mestrandos e doutorandos, bem como examina os pontos de vista desses orientadores - franceses e brasileiros - sobre como seus orientandos constroem a relação com a palavra de outrem no processo de escrita acadêmica.

O terceiro eixo é o que agrupa o maior número de pesquisas: doze artigos ao todo, os quais apresentam reflexões sobre dispositivos e recursos didáticos. A interlocução com os pares na formação profissional e a construção da identidade do professor-autor-formador, de Everton Vargas da Costa e Margarete Schlatter, é um trabalho que analisa a construção da identidade do professor-autor-formador em contexto acadêmico. Nessa pesquisa etnográfica, os autores investigam as trajetórias, em eventos de formação (COSTA, 2013, 2018), de duas professoras de português como língua adicional (PLA) de um curso de Letras em uma universidade federal do sul do Brasil. Para Costa e Schlatter, é nas interações entre os pares seja quando negociam a criação de uma unidade didática, seja quando preparam a apresentação dos materiais em um evento acadêmico - que suas identidades profissionais de professoras-autoras-formadoras são construídas.

Em Academic writing in higher education: focusing on courses of graduate programs of a public Brazilian University, Carlla Dall'Igna e Maria Ester Wollstein Moritz apresentam os resultados da pesquisa que fizeram acerca de como o letramento da escrita acadêmica é abordado em dezesseis programas de pós-graduação de uma universidade pública brasileira. Nesse mapeamento, constatam que apenas $50 \%$ dos programas oferecem disciplinas que incluem escrita acadêmica, e ainda, que cada disciplina aborda o letramento diferentemente. Resultado alarmante que leva as autoras - e, por extensão, leva-nos também - a concluir que os letramentos acadêmicos continuam desprestigiados nas instituições de ensino superior brasileiras - daí a urgência de se colocar na agenda contemporânea das pesquisas discussões teóricas e práticas sobre os letramentos acadêmicos, tal como propõe este dossiê.

Resultados igualmente desanimadores são constatados em Compreensões sobre $a$ 
formação para o/do ato de escrever na esfera acadêmica sob a perspectiva histórico-cultural, de Karoliny Correia e Aline Cassol Daga. Para discutir os processos de instrução e desenvolvimento dos sujeitos no "ato de escrever" gêneros da esfera acadêmica, as autoras analisam, sob uma perspectiva histórico-cultural que tem como base os estudos bakhtinianos e vigotskianos, os usos da escrita em uma disciplina de Leitura e Produção Textual (LPTA) de um curso de Letras Português, ofertado na modalidade a distância, em uma universidade do sul do Brasil. Correia e Daga chegam a uma conclusão não muito otimista: a de que a assinatura do ato parece estar à margem do processo, em um movimento mais estacionário que progressivo, uma vez que os interactantes não se apropriam efetivamente dos objetos culturais envolvidos nos eventos de escrita acadêmica.

Virginia Orlando, em Enseñanza universitaria y literacidades académicas: perspectivas presentes y horizontes futuros, também discute os processos de leitura e escrita no ambiente universitário, mais especificamente, a autora analisa três "metaeventos" letrados desenvolvidos em duas oficinas de leitura e escrita que acompanhou, como observadoraparticipante, em uma universidade pública de Montevideo, no Uruguai. As oficinas foram oferecidas a docentes de diferentes áreas de conhecimento dessa instituição e os "metaeventos" revisados a partir da "pedagogia dos multiletramentos" (KALANTZIS e COPE, 2005). Os resultados apontam para a necessidade de repensar essas práticas (letradas, discursivas e sociais) e propor ações didáticas mais eficazes envolvendo leitura e escrita nos diferentes campos disciplinares em uma universidade.

Em Letramento acadêmico e formação do professor de língua materna: um estudo de caso em um curso de letras, Márcia Adriana Dias Kraemer e Ramunielly Bonatti Longaretti investigam os letramentos acadêmico-científicos dos discentes em fase final de formação no Curso de Licenciatura em Letras, Português e Espanhol, da Universidade Federal da Fronteira Sul, campus Realeza. Os resultados da análise, com base nos pressupostos teóricos e empíricos referentes ao desenvolvimento de capacidades de leitura e escrita, são promissores, e demonstram que os sujeitos da investigação apresentam participação periférica legítima como aprendizes das práticas letradas envolvendo ensino-pesquisa-extensão. A práxis acadêmica com programas que privilegiam, por exemplo, estágios docentes supervisionados - possibilita a inserção proficiente desses futuros professores em contextos educacionais.

O trabalho de Camila Dilli, Bruna Morelo e Margarete Schlatter, intitulado O ensino de leitura voltado a universitários indígenas: análise de uma unidade didática à luz dos estudos de letramento acadêmico, apresenta um material didático - em específico, uma unidade sobre abstracts - elaborado especialmente para um curso em uma universidade federal brasileira, como parte de um projeto de Ações Afirmativas para permanência de estudantes indígenas nessa universidade até a diplomação. As autoras analisam de que modo as tarefas de leitura e escrita propostas nessa unidade temática, pensadas para estudantes de grupos prioritários, e apoiadas nos Estudos de Letramento Acadêmico (ACLITS) e nas diretrizes pedagógicas que privilegiam práticas sociais, são válidas, pois rompem com orientações históricas e ideologias dominantes nas práticas universitárias de ensino. 
No artigo O gênero mapa mental e o letramento do professor de línguas, Luciane Sturm reconhece que a formação universitária do professor de línguas é sempre um desafio, visto que o estudante dispõe de um curto período para reconstruir sua identidade e se afirmar como professor autônomo e letrado. Levando em conta tal desafio, a autora lança outro: o de apresentar, descrever e argumentar em favor do uso do mapa mental (BUZAN, 1995) como facilitador de aprendizagem do estudante ao longo de sua formação em Letras. A autora aposta na potencialidade dos mapas mentais para o desenvolvimento da cognição, da criatividade e do letramento do estudante, por isso elabora uma proposta pedagógica para o seu uso, e a descreve em seu artigo.

Dalve Oliveira Batista-Santos, em O professor universitário como agente letrador: interfaces com o desenvolvimento do letramento acadêmico, investiga a atuação do professor universitário enquanto agente de letramento (KLEIMAN, 2006) na mediação e no gerenciamento de diferentes vozes em uma atividade dialógica de construção de sentidos. Trata-se de uma pesquisa interpretativista, que utilizou a metodologia do Pensar Alto em Grupo (PAG) e baseou-se nos pressupostos dialógicos do Círculo de Bakhtin e dos Novos Estudos do Letramento como fundamentação teórica. Os dados gerados revelam que é nas ações docentes (de refutar, acatar e ampliar as ideias) que o letramento acadêmico se constrói: no caso analisado, a professora-pesquisadora se constitui agente letradora ao mediar, negociar, gerenciar as vozes leitoras das participantes.

Incidencia de las trayectorias disciplinares en la escritura en el posgrado desde la perspectiva de los estudiantes, de autoria de María Isabel Pozzo, tem como proposta apontar os efeitos resultantes das práticas de escrita na pós-graduação - especificamente, do mestrado em ensino universitário da Universidade Tecnológica Nacional de Rosario, na Argentina -, com base na hipótese de que as abordagens sobre essas práticas são diferentes em cada disciplina e/ou trajetória acadêmica. O material de análise foi coletado a partir das respostas de pósgraduandos a questionários sobre a percepção das dificuldades relacionadas à prática de escrita nas diferentes carreiras, e os resultados sinalizam que há pouca ou nenhuma coincidência entre os graduados da mesma disciplina e que as trajetórias disciplinares são fenômenos complexos.

O artigo Experiências com a escrita na pós-graduação brasileira: uma proposta de diálogo com os letramentos acadêmicos, de Guilherme Brambila, segue na temática deste eixo ao discutir os lugares da escrita acadêmica na pós-graduação brasileira. Dessa vez, a análise é voltada para as postagens de pós-graduandos no grupo chamado "Bolsistas Capes" da rede social Facebook, espaço em que relatam suas experiências sofríveis ao produzirem textos do gênero acadêmico - nessa pesquisa especificamente, Brambila seleciona como corpus três postagens em que os estudantes confessam suas dificuldades de escrever suas dissertações. Tal estudo guia-se pelos pressupostos dos letramentos acadêmicos no contexto brasileiro (FISCHER, 2010; FIAD, 2011) e a análise guia-se, metodologicamente, pelo paradigma indiciário (GINZBURG, 1986).

No texto Da dimensão sociocomunicativa à arquitetura textual na abordagem didática 
do gênero resenha acadêmica, Regina Celi Mendes Pereira e Evandro Gonçalves Leite apresentam uma experiência didática a partir das atividades de produção - escrita e reescrita - da resenha acadêmica com estudantes de graduação em Letras. Ancorados nos aportes teórico-metodológicos do Interacionismo Sociodiscursivo filiados à perspectiva dos Letramentos Acadêmicos, os autores concluem que, no processo de escrita do gênero resenha, há imbricamento de aspectos sociocomunicativos, discursivos e linguísticos; destacam, ainda, que a escrita acadêmica é uma atividade que envolve questões que vão além da materialidade textual, pois demandam vivências e agentividade, já que são essas práticas (sociais) que poderão assegurar aos graduandos melhores condições de apropriação do gênero.

Para finalizar este eixo, Cynthia Agra de Brito Neves, em Les genres académiques au ProFIS: un rapport d'expérience et d'inclusion sociale à l'Unicamp, apresenta o Programa de Formação Interdisciplinar Superior (o ProFIS) da Unicamp, um curso piloto, criado em 2011, e oferecido a alunos de escolas públicas de Campinas. No artigo, a autora assume a vez e a voz de professora-pesquisadora para relatar sua experiência, em 2017, na disciplina de Leitura e Produção de Textos Acadêmicos II, que ministrou para os alunos do ProFIS. Neves analisa as produções de textos acadêmicos desses alunos, como a escrita da resenha crítica e do artigo científico, e o gênero oral seminários, apontando, nessas atividades de letramento, sucessos e dificuldades de ensino e de aprendizagem de tais gêneros acadêmicos.

O quarto eixo é constituído por um artigo que versa sobre os sistemas de métrica de citações. Discurso acadêmico: a regulação do poder disciplinar e do panóptico, de Beatriz Gil e Fernanda Correa Silveira Galli, apresenta uma reflexão sobre a operacionalização do poder disciplinar e do panóptico nas práticas que circundam o discurso acadêmico na contemporaneidade. Com base na metodologia genealógica foucaultiana, as autoras analisam os sistemas de métricas acadêmico e científicas do banco de dados Google Acadêmico e do índice $\mathrm{H}$, os quais são considerados marcadores acadêmicos de produtividade. Como resultados, Gil e Galli assinalam que os princípios da visibilidade e da inverificabilidade do panóptico funcionam como ferramentas disciplinares no contexto acadêmico, o que leva os pesquisadores a se transformarem, inconscientemente, em corpos dóceis diante da maquinaria de produção científica e, por consequência, se enquadrarem na normalidade determinada pelas instituições.

O quinto eixo agrega, por fim, cinco artigos que tratam da temática dos gêneros do discurso. A produção escrita de artigo no contexto acadêmico: as contribuições da abordagem sistêmico-funcional, de Záira Bomfante dos Santos e Flaviane Faria Carvalho, traz uma investigação sobre como a abordagem da linguística sistêmico-funcional, em diálogo com a sociorretórica, pode ser aplicada na produção de artigos científicos produzidos por alunos das áreas de Humanidades e Ciências da Natureza e Matemática. Como resultados, as autoras: (i) destacam a citação como estratégia retórica mais significativa nos artigos, em ambas as áreas, e (ii) apontam que as Ciências Humanas tendem a priorizar menos as considerações sobre os resultados da pesquisa do que as Ciências da Natureza e Matemática, que, por sua vez, valorizam os impactos e a aplicação dos resultados na sociedade. 
Sandra Dias Loguercio, no artigo intitulado Entre buscar contribuir e la contribuition: a modalização em resumos científicos em português e francês, relata uma investigação comparativa - de base onomasiológica e semasiológica - sobre as marcas de modalização presentes em resumos científicos produzidos em português e em francês, com a finalidade de contribuir para uma melhor caracterização desse gênero. Como resultados, Loguercio destaca que a linguagem utilizada nos resumos confirma a preponderância de uma postura científica e, ao mesmo tempo, demonstra que os resumos em português se caracterizam pela postura de intenção (volitiva), enquanto os resumos em francês se configuram pela postura de autoafirmação (avaliativa). Para a autora, esses são aspectos importantes e devem ser considerados pela pedagogia das línguas e da tradução.

Em Les entrées en matière non théoriques dans des mémoires de master et des articles de revues, Bertrand Daunay e Daniel Bart comparam introduções de dissertações de mestrado e de artigos de professores doutores - da área da didática, em língua francesa - e descrevem as especificidades do discurso desse gênero acadêmico. Na investigação, os autores buscam discutir o papel das referências feitas pelos pesquisadores a outros campos além do teórico, o que eles consideram um desafio no processo de aprendizagem da escrita acadêmica. Como resultado da análise exploratória, Daunay e Bart mapeiam as convergências formais das referências não teóricas presentes nos textos analisados - dos professores e dos estudantes-, e, ainda, as diferenças relacionadas ao tipo de referência empregada.

No artigo Letramento acadêmico: dimensões escondidas em rasuras em contexto digital, Tatiane Henrique Sousa Machado, Cristiane Carneiro Capristano e Neiva Maria Jung, ancoradas na perspectiva dos Letramentos Acadêmicos, analisam as rasuras em artigos de opinião elaborados por acadêmicos, em contexto digital. Com base em uma visão enunciativodiscursiva da linguagem, as autoras concluem que as rasuras indicam quatro negociações (cf. AUTHIER-REVUZ, 1998) mais regulares, as quais dizem respeito à seleção do léxico, à norma linguística, ao enquadramento do gênero e aos posicionamentos expressos nos textos. Essas negociações emergem no gênero artigo de opinião ou como mostradas (mas, opacas) ou como escondidas (não explicitadas) - lacunas que são apontadas na reflexão como efeitos da pluralidade de sentidos das relações de poder instituídas e reafirmadas nas práticas letradas.

Denis Leandro Francisco, em Letramentos acadêmicos em PLE: escrevendo a sociedade e a cultura brasileira na Coreia do Sul, apresenta uma discussão sobre a prática de escrita com graduandos de Estudos Brasileiros no contexto do ensino superior sul-coreano. Com base no modelo ideológico de letramento (STREET, 1995), o autor discute a escrita acadêmica - do gênero portfólio - como dispositivo didático que pode desenvolver tanto a autonomia quanto o posicionamento crítico dos estudantes. Como considerações finais, Francisco aponta, por um lado, os desafios encontrados no contexto coreano analisado, os quais dizem respeito à pouca familiaridade dos graduandos com as práticas de letramento acadêmico, particularmente o gênero portfólio; por outro lado, avalia essa "prática pedagógica" de produção escrita como relevante para a aprendizagem da língua-cultura alvo dos estudantes no contexto acadêmico. 
Todos os artigos selecionados para este número temático apresentam pesquisas, brasileiras e estrangeiras, que poderiam integrar mais de um eixo, até porque o modo como eles foram pensados não é estanque e os trabalhos contemplados neles dialogam entre si bakhtinianamente falando. Ademais, o presente dossiê se destaca pela quantidade, qualidade e diversidade de artigos submetidos, o que mais uma vez comprova a relevância do tema e a urgência de discuti-lo na contemporaneidade. Por fim, agradecemos aos autores e às autoras, do Brasil, da Argentina, da França e do Uruguai, que contribuíram com suas reflexões acerca dos letramentos acadêmicos neste dossiê.

\section{Referências}

AUTHIER-REVUZ, J. Palavras incertas: as não coincidências do dizer. Campinas: Editora da UNICAMP, 1998.

BARTON, D. Literacy: an introduction to the ecology of written language. London: Blackwell, 1994.

BUZAN, T. The mind map book. 2. ed. London: BBC Books, 1995.

COSTA, E. V. Práticas de formação de professores de português língua adicional em um Instituto Cultural Brasileiro no exterior. Dissertação (Mestrado em Letras). Porto Alegre: Universidade Federal do Rio Grande do Sul, 2013.

COSTA, E. V. Eventos de formação de professores de português como língua adicional: a organização das práticas e as trajetórias de participação em um estudo interpretativo sobre aprender a ensinar. Tese (Doutorado em Letras). Porto Alegre: Universidade Federal do Rio Grande do Sul, 2018.

FIAD, R. S. A escrita na universidade. Revista da ABRALIN, v. Eletrônico, n. Especial, p. 357-369, 2a parte, 2011. https://doi.org/10.5380/rabl.v10i4.32436

FISCHER, A. Os usos da língua na construção de sujeitos letrados: relações entre a esfera escolar e a acadêmica. Acta Scientiarum. Language and Culture, Maringá, v. 32, n. 2, p. 215224, 2010. https://doi.org/10.4025/actascilangcult.v32i2.9257

GEE, J. P. Social linguistics and literacies: ideology in discourses. London: Falmer, 1996.

GINZBURG, C. Mitos, Emblemas, Sinais: morfologia e história. São Paulo: Companhia das Letras, 1986.

KALANTZIS, M.; COPE, B. A multiliteracies pedagogy: a pedagogical supplement. In: KALANTZIS, M.; COPE, B. (Eds.) Multiliteracies: literacy learning and the design of social futures. London and New York: Routledge, 2005. p. 239-248.

KLEIMAN, A. B. Processos identitários na formação profissional - O professor como agente de Letramento. In: CORRÊA, M.; BOCH, F. Ensino de língua: representação e letramento. Campinas, SP. Mercado das Letras, 2006.

STREET, B. V. Literacy in theory and practice. Cambridge: Cambridge University Press, 1984.

STREET, B. V. Social literacies: critical approaches to literacy development, ethnography and education. London: Longman, 1995. 